\title{
Investigation of Valve Tip End Wear Mechanism of a Four-Cylinder Automotive Engine Under High-Speed Application
}

\author{
Yashkumar Gandhi (1) - Ninad Pawar • Nanasaheb Zoal • \\ Gurunathan Ramnathan
}

Submitted: 2 August 2021/in revised form: 1 September 2021/ Accepted: 27 September 2021/Published online: 20 October 2021 (C) The Author(s) 2021

\begin{abstract}
This work investigates the causes of wear occurring at the engine valve tip end after 400 hours of engine operation. Fatigue wear was observed on the valve tip at the product development stage of the engine, which is going to be used in an automotive vehicle. Valves were assembled on a gasoline/CNG fuel-based four-cylinder IC engine. In this engine, tip end wear was prominent during high-speed testing conditions as compared to other types of engine tests. The chemical composition of worn surfaces was verified by spectroscopy. The microstructures, grain sizes and surface roughness were determined by optical microscopy and surface roughness tester. To evaluate the wear mechanism, valve tip end worn surfaces were analyzed using Scanning electron microscopy. The SEM analysis indicates the initiation of micropits and subsequent propagation of the fatigue wear during engine operating conditions. The residual stresses were measured at valve tip end surfaces and subsurfaces using X-ray diffraction techniques. Several investigations employing multiple techniques were carried out to identify the root cause of failure while comparing results against those of untested valves. Parameters that can affect valve tip end properties were identified in the study and countermeasures provided, and that lead to successful completion of the testing with the same operating condition.
\end{abstract}

Keywords Engine valve - Pitting - Fatigue wear . Hardening $\cdot$ Stress relieving

Y. Gandhi $(\bowtie) \cdot$ N. Pawar · N. Zoal · G. Ramnathan Research \& Development Department - Engine Valves, Varroc Engineering Ltd., Aurangabad 431136, India

e-mail: yashgandhi013@gmail.com;

yashkumar.gandhi@varroc.com

\section{Introduction}

IC engine used for automobile application must undergo rigorous testing to understand friction and wear of engine valve train components. The tip end wear of engine valves was reported in a four-stroke, four-cylinder engine configuration with a type II valve train mechanism and a capacity of $1.2 \mathrm{~L}$. The same engine was used for gasoline and CNG fuel application with a different exhaust valve design. When the engine is under development, the engine train components must pass through several severe tests to check the effect of extreme loading conditions on valve train components. Hence, the engine was subjected to maximum high-speed application. The speed of the camshaft was 3200 RPM at the engine's maximum speed. Based on the engine cycle and duration of the test, the valve tip end has experienced approximately 76.8 million cycles at the end of testing. When the engine is tested under maximum speed conditions, all the valve train components are subjected to extreme wear conditions. An increase in the engine speed may increase valve seating velocity, vibration and noise. From a tribological point of view, an increase in engine speed may increase contact stresses at the valve tip end. Hence, the valve tip material should have sufficient fatigue strength to endure engine life to withstand much higher contact stresses during engine operating conditions.

Several factors may affect the excessive tip end wear of the valve, which are discussed in the following section of the article. A schematic diagram of the type II valve train mechanism is shown in Fig. 1, where the Hydraulic lash adjuster and RFF mechanism are provided to reduce the friction of the valve train system [1]. In the component pair like RFF-valve tip, contacts occur between curve surfaces 


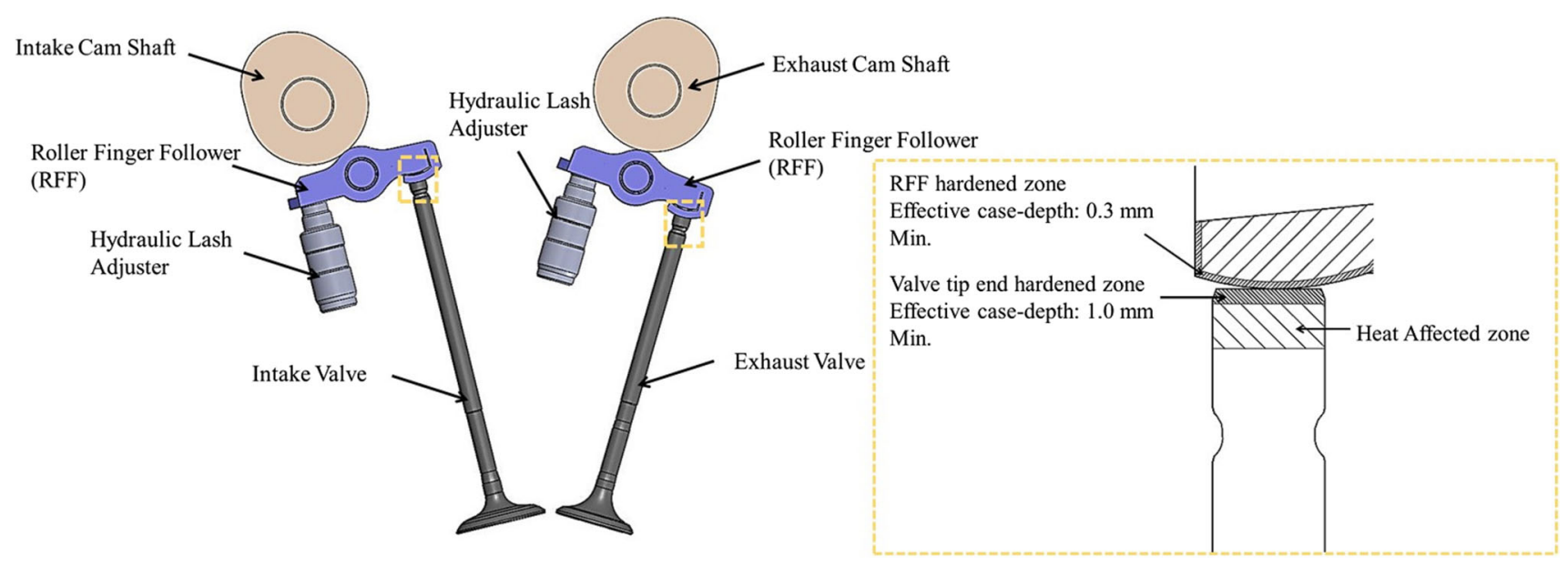

Fig. 1 Type II valve train mechanism. The dashed lines enclose the region of contact surfaces

with different curvature radii; thus, the load is carried by a minimal contact area which is resulting in high stresses. This technology has become popular for engine developers, as using a type II mechanism over direct contact type (type I) has contributed to reducing the friction at low and high speeds. When redesign of the tribological system is required, it is advisable to control the wear mechanism in real components, where the main cause of failure is the faulty manufacturing process, which involves improper heat treatment, microcracks, stress concentration, etc. Recently, modeling and simulation in engine designing has been considered important tools for optimizing and predicting the wear of any mechanical system. The cam surface and valve tip end profile also influenced the maximum wear depth and distributions [2]. Contact fatigue or surface pitting type failure is commonly found in the ball or roller bearings. A similar kind of failure was reported for gears, cams and gear couplings [3]. The failure analysis of two rocker arms from a heavy-duty diesel engine showed a banded microstructure and spheroidization of cementite in pearlite, resulting from an unsuitable normalizing heat treatment [4]. Other studies also show excessive wear on the rocker arm due to improper austenitization parameters or inappropriate inductor shape, leaving free ferrite in the induction hardened region [5]. Another study attributed the fatigue failure of the rocker arm to stress concentration [6]. Till now, no studies have been reported showing pitting wear phenomena on engine valve tip end.

The present study investigates the causes of excessive wear at the valve tip end. Various causes were identified from the valve manufacturing point of view that might affect the valve tip end properties. Based on those causes, improvements are done in the processes and implemented during valve production. Scanning electron microscopy was used to determine the type of wear mechanism and its behavior. The chemical composition of the worn parts and new parts was performed using optical emission spectroscopy, and the microstructure was identified by optical microscopy. Microhardness tests and surface measurements were also taken. X-ray residual stress analyzer was used to know the type of residual stresses present at the surface and subsurface of the valve tip end. SEM analysis shows the fatigue wear phenomenon at the valve tip end.

\section{Ishikawa Diagram of Valve Tip Pitting}

Insufficient valve tip material hardness corresponding to roller finger follower (RFF) may lead to excessive wear on the valve tip end. As the initial law of tribology says, when two surfaces are in contact with each other, and there is a sliding/rolling motion between them, the material with lower hardness may wear out more than material with higher hardness provided the chemical composition of both the materials is equivalent. Hence, the initial idea was to improve the hardness of the valve tip end close to the hardness of the counterpart (RFF).

A decrease in lubricating film thickness leads to excessive wear of the mating surfaces as the wear mechanism will change from wet to dry. The use of lowviscosity oil has reduced lubricating film thickness between contact surfaces [7]. The presence of wear debris in lubricating oil can also cause the wear of the mating surface. Since the wear mechanism was fatigue type instead of abrasion or abrasive type, this cause was eliminated, and it was observed that the oil was appropriately filtered during engine operation. In addition to that, if any residual magnetism is present in the mating material, this wear debris may be entrapped between two surfaces and further contribute to the wear. The residual magnetism compared on worn parts and new parts and the value was close to zero Gauss. 
Material microstructure largely contributes to the wear resistance behavior. The material grade of the valve tip was SUH-11, which is martensitic steel. The microstructure of hardened martensite is the platelike structure within grains. Grain size can also affect the mechanical properties of the material. Improvement in the material microstructure can only be possible with a proper heat treatment process. Any inclusion in the material may also act as a crack initiation site at such high-cycle loading conditions.

Fundaments of tribology studies indicate that an increase in surface roughness of the material increases the peak to valley distance. When the material with higher surface roughness is subjected to the material with lower surface roughness, the higher roughness part will wear out more provided all other parameters of both the materials are identical. It is because two asperities come into contact, and microweld joints are formed at mating surfaces. Further, it may break during sliding forces and split up as wear debris. The presence of residual stresses is also a significant parameter to be considered when the application where contact stresses are present. When contact stresses exceed the yield limit of the material, void formation may occur at the surfaces, and cracks can further propagate in the material. Hence, the value of residual stress and the nature of stress must also be considered during the processing of components. Based on the Ishikawa diagram as shown in Fig. 2, the causes related to engine valve manufacturing were identified and countermeasures implemented in the manufacturing of the valve. The testing was found to be successful after implementing the countermeasures.

\section{Materials and Methods}

A schematic representation of valve tip end and RFF assembly is shown in Fig. 1, together with the hardened region on components. The samples were prepared from the valve tip end and RFF to analyze the chemical composition of steel constituents by optical emission spectroscopy (Spectro, Spectro Maxx LMM14). The details of the material's chemical composition are shown in Table 1. The material used for the valve tip end is mediumcarbon, $\mathrm{Cr}-\mathrm{Si}$ martensitic valve steel. The material is in hardened and tempered condition, and microstructure reveals tempered martensite and fine alloy carbides, as shown in Fig. 3. To increase surface hardness and contact fatigue resistance of the material, selective hardening was used on the engine valve tip end and RFF. The microhardness and effective case depth of hardening is shown in Table 2.

The worn surfaces were first examined using a stereoscope (Zeiss, Stemi 508). Higher-magnification analysis was conducted using a scanning electron microscope (Tescan, Vega 3) to understand the creation of micropits. The SEM micrographs were recorded in secondary electron imaging (SEI-SEM) mode. A surface roughness tester (Mitutoyo, Surftest SJ-410) was used to measure the surface roughness of the valve tip end. Contour measuring system (Mitutoyo, FTA C-3000) was used to determine the pitting depth of the valve tip end surface. To determine the microstructure of pitted and non-pitted samples, longitudinal sections (parallel to valve stem axis) and transverse (perpendicular to valve stem axis) sections were prepared,

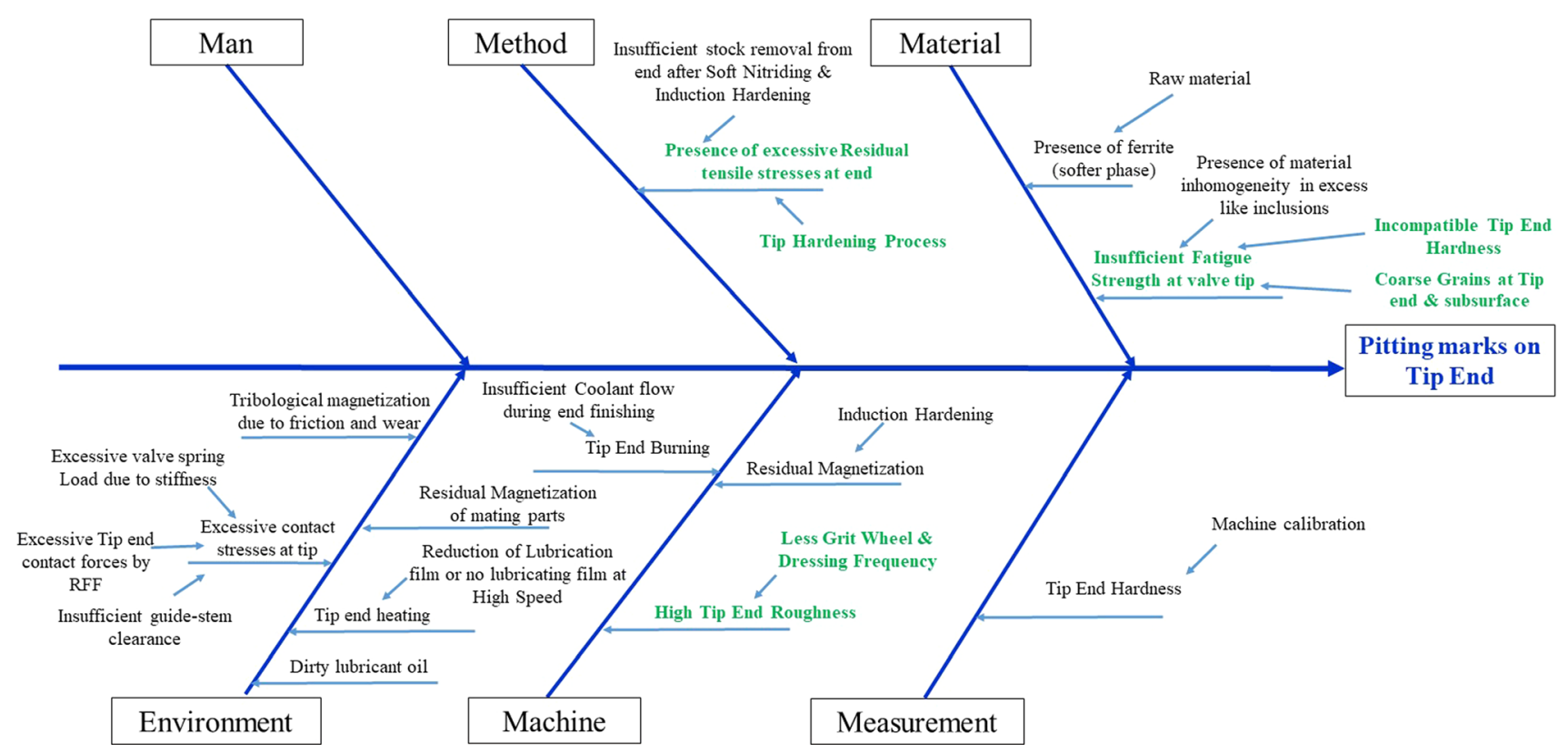

Fig. 2 Ishikawa diagram of valve tip end wear 
Table 1 Chemical composition (wt.\%) of steels used for a valve tip end and roller finger follower

\begin{tabular}{lcccccccc}
\hline Component & $\mathrm{C}$ & $\mathrm{Si}$ & $\mathrm{Mn}$ & $\mathrm{Ni}$ & $\mathrm{Cr}$ & $\mathrm{S}$ & $\mathrm{P}$ & Others \\
\hline Valve tip end & 0.51 & 1.39 & 0.38 & 0.29 & 8.17 & 0.019 & 0.016 & $\mathrm{Fe}$ \\
$\begin{array}{l}\text { Roller finger } \\
\text { follower } \\
(\mathrm{RFF})\end{array}$ & 0.15 & 0.29 & 1.12 & - & 0.99 & 0.028 & 0.019 & $\mathrm{Fe}$ \\
\hline
\end{tabular}

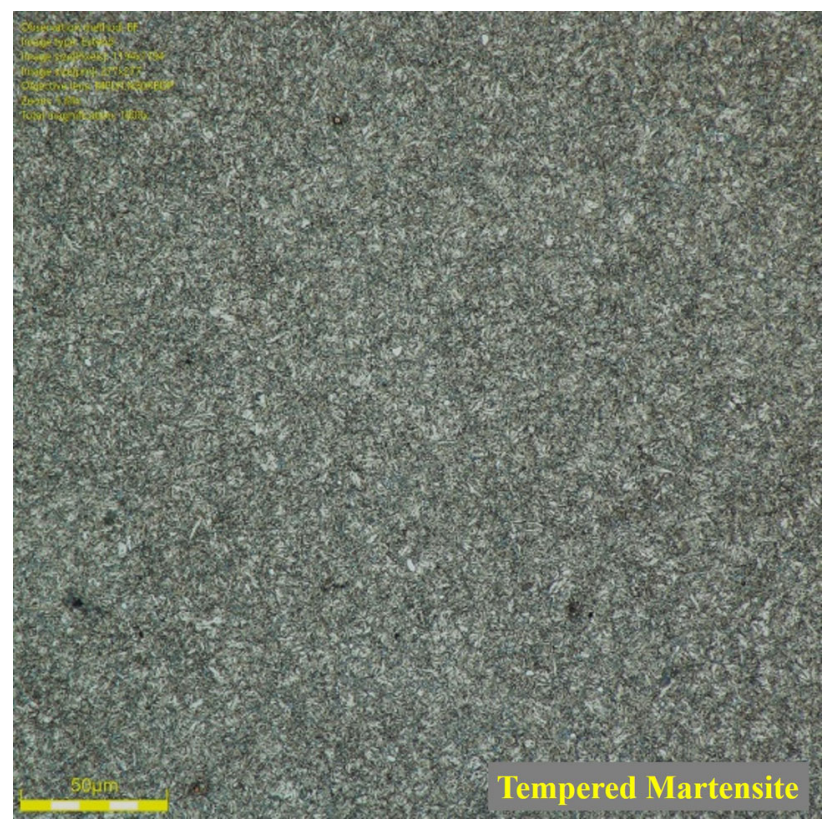

Fig. 3 Microstructure of SUH-11 material (hardened and tempered)

Table 2 Hardness (HRC) values and required effective case depth $(\mathrm{mm})$ of the region experiencing additional hardening treatment

\begin{tabular}{lccc}
\hline $\begin{array}{l}\text { Hardened region } \\
\text { of component }\end{array}$ & $\begin{array}{c}\text { Before } \\
\text { improvement } \\
\text { (HRC) }\end{array}$ & $\begin{array}{c}\text { After } \\
\text { improvement } \\
\text { (HRC) }\end{array}$ & $\begin{array}{c}\text { Effective case } \\
\text { depth (mm) }\end{array}$ \\
\hline Valve tip end & $57-59$ & $60-62$ & $1.0 \mathrm{Min}$. \\
$\begin{array}{l}\text { Roller finger } \\
\text { follower }\end{array}$ & $62-64$ & $62-64$ & $0.3 \mathrm{Min}$. \\
\hline
\end{tabular}

mounted in resin, polished and analyzed by a digital optical microscope (Olympus, DSX-510). The oxidizing technique was used to evaluate the grain size of the martensitic structure of the valve tip end as per ISO 643. After oxidizing heat treatment, the samples were polished lightly and etched with 5\% Nital to reveal the prior austenite grain boundaries. And that helps in analyzing the grain size of the hardened martensitic structure. Hardness was measured on a microhardness tester (Buehler, Wilson VH 1202), and Rockwell hardness values given by software were considered as per ASTM E140. Microhardness measurement was taken with $50 \mathrm{gm}$ of load from surface to $2 \mathrm{~mm}$ depth in a zigzag manner, and the further interval is considered as 25 microns up to $0.2 \mathrm{~mm}$. And further indents interval increased at the same load. Residual stress measurements were taken on the surface and subsurface using an X-ray residual stress measurement instrument (Proto, iXRD).

\section{Results and Discussion}

\section{Macroscopic Observation}

The stereoscopic image show pits at a specific region of the valve tip end surface. The pitting phenomenon was not observed in all the valve tips assembled in the engine. In few valves, initiation of pitting is also evident. However, pitting has not been initiated yet in some of the valves, even though these valves were from the same engine (Fig. 4a).

The extent of pitting wear on the valve tip end's surface was more aggressive than wear on counterpart RFF (Fig. 4c). The wear on the tip end of valves was more prominent at one side of the overall tip end surface, as shown in Fig. 4b. The maximum depth of wear was not located exactly at the center of the valve tip end surface, whereas wear was more prominent on the chamfer side of the valve tip end surface. Based on macroscopic observation, the valve tip end surface could be divided into two zones. The first zone (A) — pink color-was matted with numerous small clusters of pits (brighter), which are located away from the center, and the second zone (B) was completely smooth with prior grinding marks. In addition to that, some circular concentric wear tracks are visible on the valve tip end surface, which might have developed during valve rotation.

\section{Scanning Electron Microscopy}

The valve tip end surface was analyzed under higher magnification with scanning electron microscopy. The tip end surface was divided into two zones based on its initiation and propagation to understand pitting behavior, as shown in Fig. 5a and b. One zone is identified near chamfer where the first pitting is initiated, and the second zone is identified toward the tip center where pitting propagated due to continuous operating conditions.

First Zone: Near Chamfer (Periphery to valve Tip end surface)

Topography shows that initially, pitting has started from the valve tip end surface. Pitting has initiated smaller void creation at localized multiple points, as shown in Figure 5d. The presence of higher localized contact stresses may contribute to these types of microvoid creation. Initial 

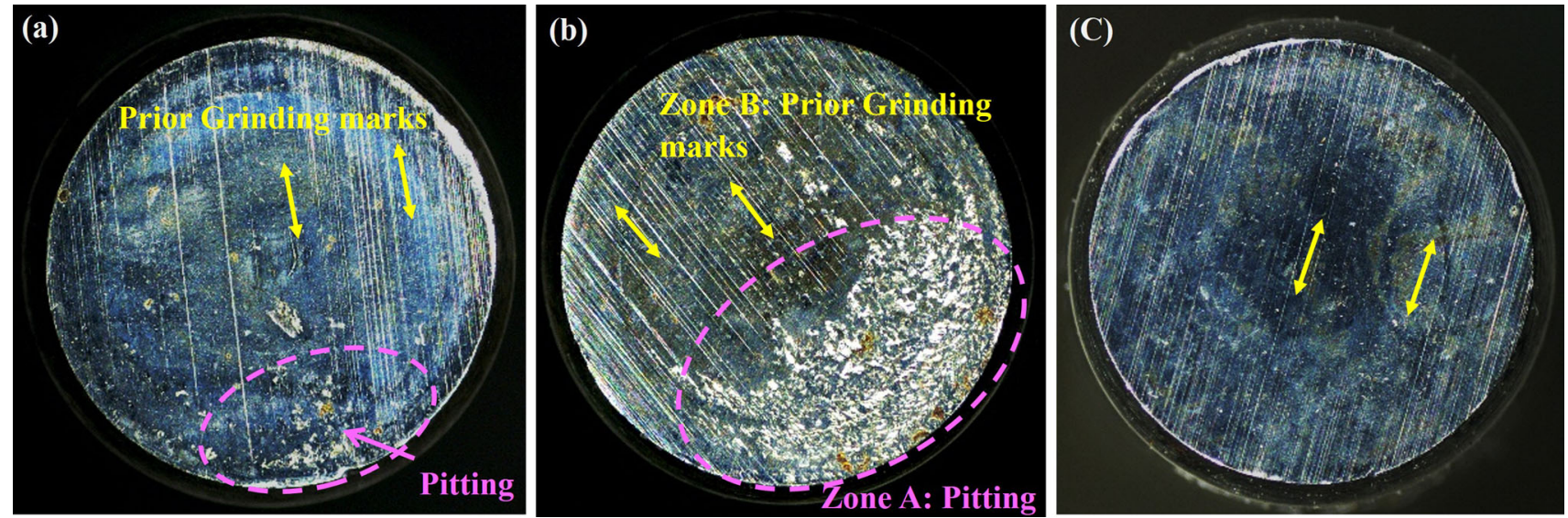

Fig. 4 Macroscopic image of valve tip pitting. a Initiation of pitting. b Prominent pitting surface. c No pitting valve

Fig. 5 a Overall surface of valve tip. b Pitting mechanism toward tip. c Pitting near valve tip center. d Pitting initiation near chamfer zone

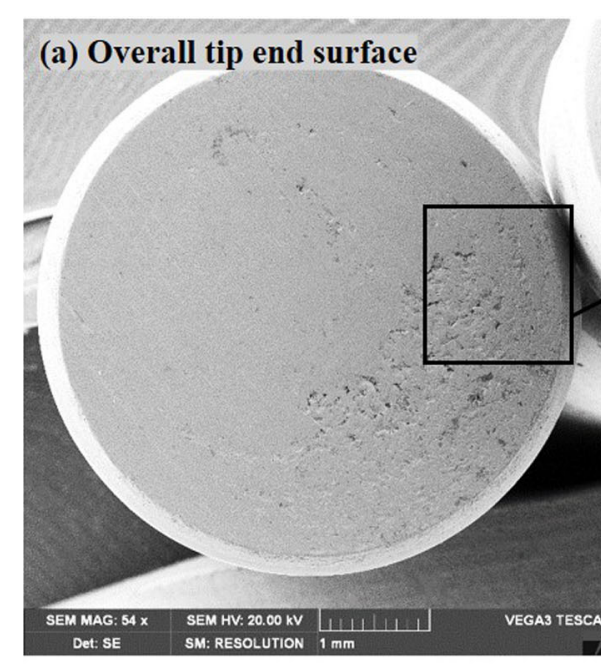

(C) Second Zone: Near tip end center

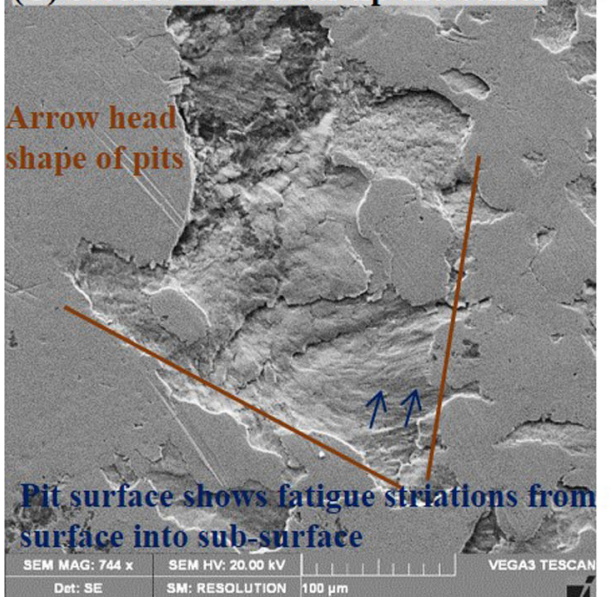

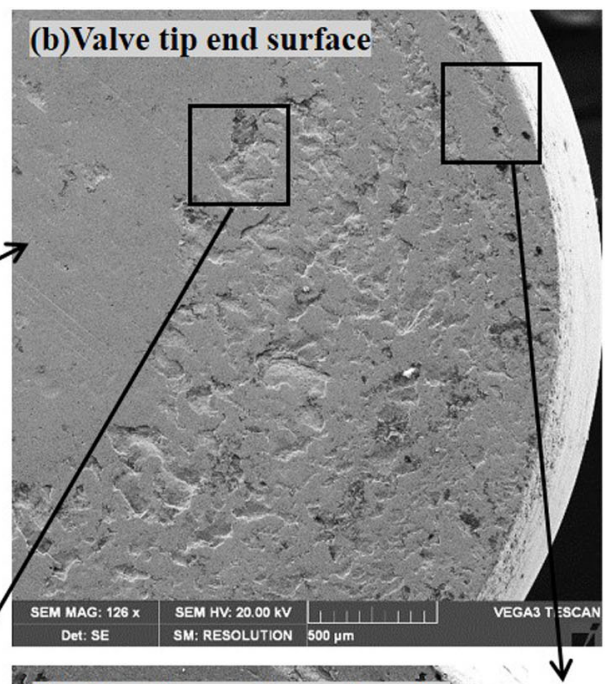

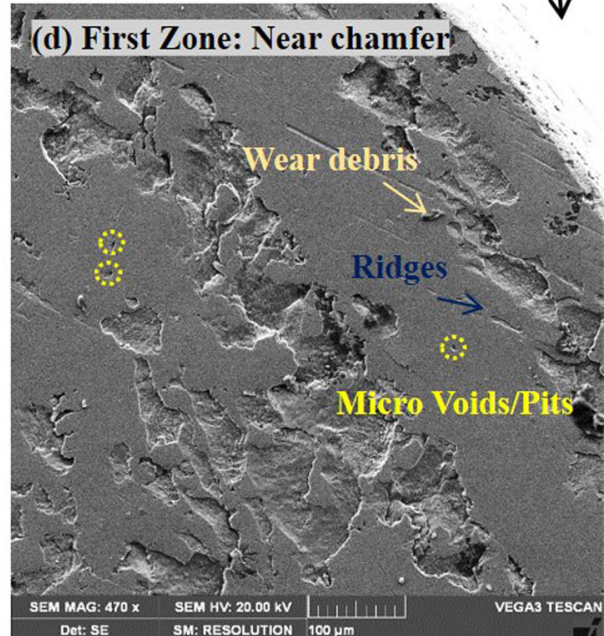

cracks might have been generated from one of those microvoids.

Further cracks generated at voids propagated down into the material subsurface region and combined with adjacent subsurface cracks and eventually lead to spalling, as shown in Figure 6. The material removed from the surface was in the fatigue mode as fatigue striations are visible in the higher-magnification image, as shown in Figure 5 (c). And the chunk of material has been removed from the surface. Further, pitting is growing along the periphery of the valve 
Fig. 6 Schematic representation of microvoid creation and further propagation

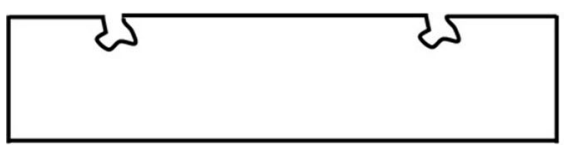

(a) Micro Voids Creation at surface

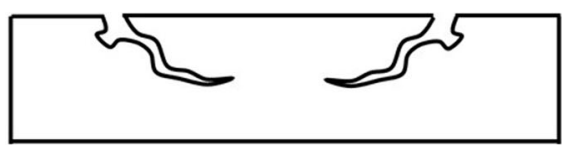

(b) Crack Propagation at sub-surface

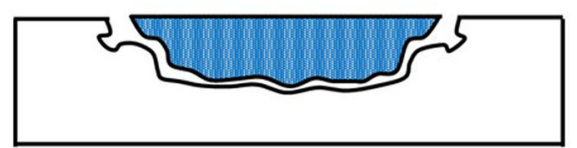

(c) Spalling of the Surface

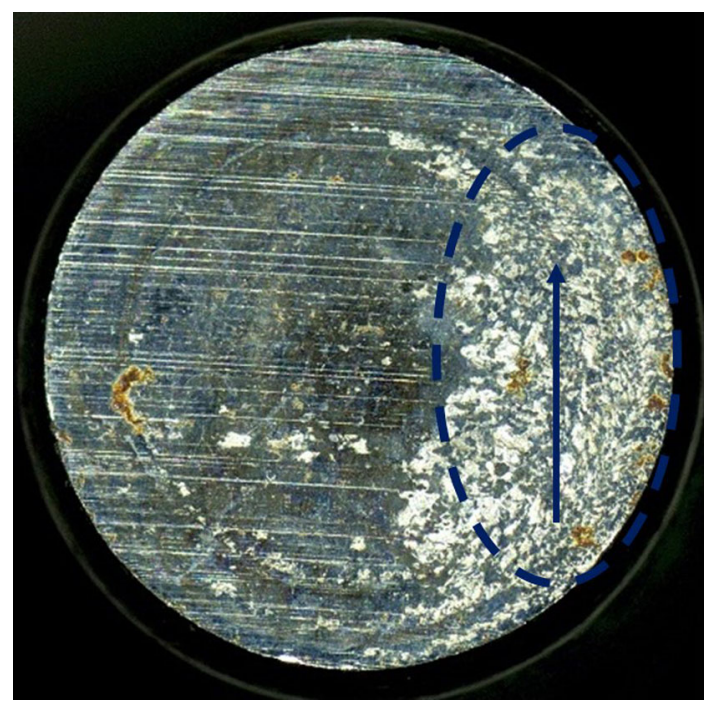

Fig. 7 Pitting depth profile measured on contour measuring machine. Surface texture measurement direction on valve tip end

tip due to valve rotation during valve operating conditions which is evident from the direction of material removal and presence of the "arrowhead" shape of pits, as shown in Figure 5 (c). Pitting is the consequence of fatigue affecting surfaces characterized by non-conformal contacts [8].

Second Zone: Toward tip center

Once the pitting has initiated from the first zone, some wear debris might have been generated due to fatigue wear. Further, this debris can also contribute to wear. The probable reason for the initiation of tip end pitting from the first zone instead of the second zone is mainly due to the geometry of RFF and valve tip end surface. The RFF design is such that during initiation of valve opening condition, the RFF surface will contact the side of tip end surface, and further, it will contact at the center of valve tip end surface. However, the mechanism of pitting is also the same as that of the first zone. In the non-conformal contact stress condition, fatigue cracks may nucleate either at the surface where stress concentrations are present or at a small depth below the surface where imperfections such as nonmetallic inclusions or soft spots in the microstructure or where excessive residual stresses are present. Once the microvoids are generated, cracks further propagate toward

the material's interior and eventually curve up, producing wear debris and pits $[8,9]$. Wear debris was observed on the valve tip end surface, as shown in Figure 5 (d). In some areas of valve tip surface, a series of ridges oriented along with the directions of microgrooves observed, generated due to abrasive wear mechanism in the presence of wear debris. These ridges are the products of free-moving debris particles transported by the lubricant and worn out the softer surface from two contacting surfaces. [10] Here, fatigue cracking has been identified by the presence of fatigue striations inside the pits that indicate the periodic propagation of crack front during cyclic loading. The previous study shows that zinc dialkyldithiophosphate (ZDDP) additives may promote fatigue crack initiation by preventing surface roughness reduction during running or creating corrosion pits on the contact surfaces. However, adding friction modifiers to the oil contained ZDDP additives may reduce friction on the contacting surface [11, 12]. In this testing, 0W16 Engine lubricating oil was used, which is fully synthetic oil and had well anti-wear and friction properties. Due to the high pressure of lubricant oil at contact surfaces, the lubricant may also flow into cracks and exerting a pumping effect which further increases the driving force for crack propagation [13]. Overall, valve tip end topography shows discrete fatigue pits evident on the contact surfaces.

\section{Surface Texture}

Valve tip end surface roughness was measured on pitted valves and the non-pitted area of the valve. The roughness of the pitted zone is $\mathrm{Ra}(\mu \mathrm{m}) 2.58$, whereas the roughness of the non-pitted zone is $\mathrm{Ra}(\mu \mathrm{m}) 0.34$. The numerous small pits in the pitted zone reflect the higher surface roughness. Tip end surface texture is determined in the direction as shown in Fig. 7. The maximum depth of pitting is observed as 21 microns.

\section{Hardness Measurement}

The hardness measurement was taken for pitted samples in the direction transverse to valve tip end surface at three 
locations, as shown in Fig. 8. The hardness in the pitted area was observed close to the specification (Fig. 9a). The hardness drop might have occurred due to the tempering effect in the pitted area during the fatigue wear mechanism. The same can be confirmed from the microstructure image as well (Fig. 10).

\section{Microstructure Observation}

Surface micrographs of the pitted valve were compared with the non-pitted valve. In the case of valve with pitting, a highly tempered martensitic structure was observed along with fine alloy carbides in the matrix. The fatigue crack initiation can also be revealed from tip end surface microstructure. The microstructure of the non-pitted valve shows the hardened martensitic structure along with fine alloy carbides. Picral etchant was used to reveal the microstructure.

As the grain size of the material is also an important parameter that can impact the strength of the material. The

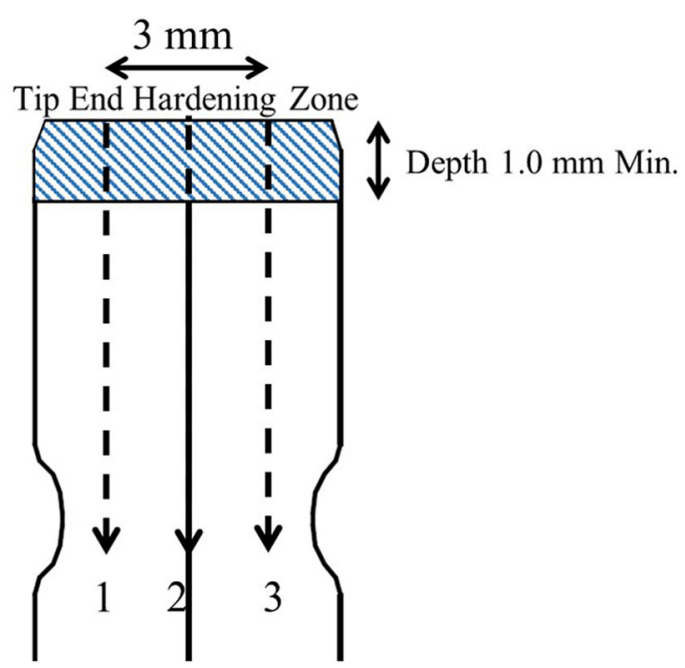

Fig. 8 Schematic diagram of hardness measurement locations

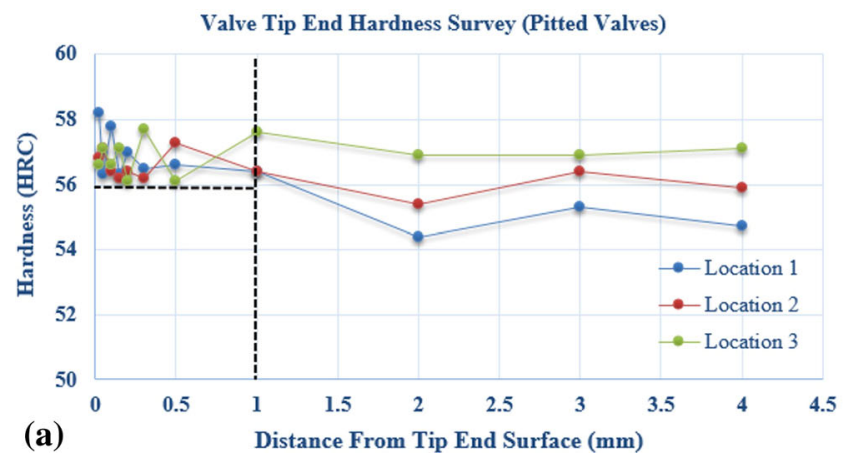

portion of the valve is hardened through an induction hardening machine followed by oil quenching. The hardening time of the specific valve is 2.5 seconds, and the power of the machine is $88 \%$ of the total $\mathrm{kW}$. The quenching process time is $2.5 \mathrm{sec}$ as the hardening and quenching treatment is incorporated in the same pick and place setup. Martensitic material is used at the valve tip end. It is not easy to visualize the grain boundaries of a fine martensite structure. The valve tip end is being heated at just above austenitizing temperature for a sufficient period as per ISO 643 and suddenly quench in the water to obtain the grain size of the material. The sample is then polished very lightly and etched with 5\% Nital. A sample was then examined under an optical microscope, and grain size analysis was carried out using Stream Basic Software. The grains shown in Fig. 11 represent the prior austenite grain boundaries of the induction hardened zone. The histogram distribution of the grain and average grain size is shown in Fig. 12. The average grain size number $(\mathrm{G})$ is found close to 11 .

\section{Residual Stress Measurement}

Residual stress analysis is an important tool to understand a tensile or compressive type of stress in the material. Generally, after the induction hardening process, some stresses are developed in the material. The nature of the stresses depends on many parameters like mass of quenching, heating temperature, cooling rate, etc. Induction/flame hardening is the process where the selective area of the part is heated above its upper critical temperature, where the material microstructure shall be fully in the gamma phase region. After hardening the material, oil quenching is carried out on the valve tip end surfaces. Initially, valve tip end hardness was maintained in the range of $58 \pm 1$ HRC. The actual hardness of RFF was noted in the range of $63 \pm 1$ HRC. Based on that observation, the actual hardness was increased up to $61 \pm 1$ HRC to withstand against the hardened RFF component. Further, grinding is done on the tip

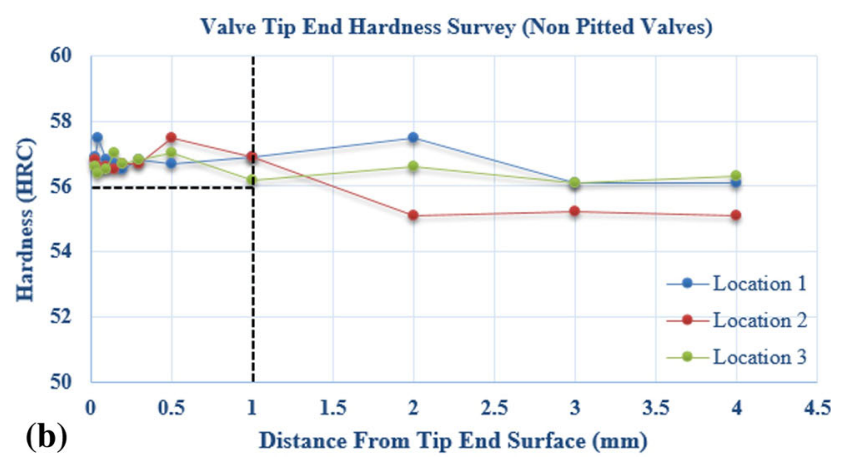

Fig. 9 Plot of hardness from tip end surface in the induction hardened zone. a Pitted valves; $\mathbf{b}$ non-pitted valves from the same engine 

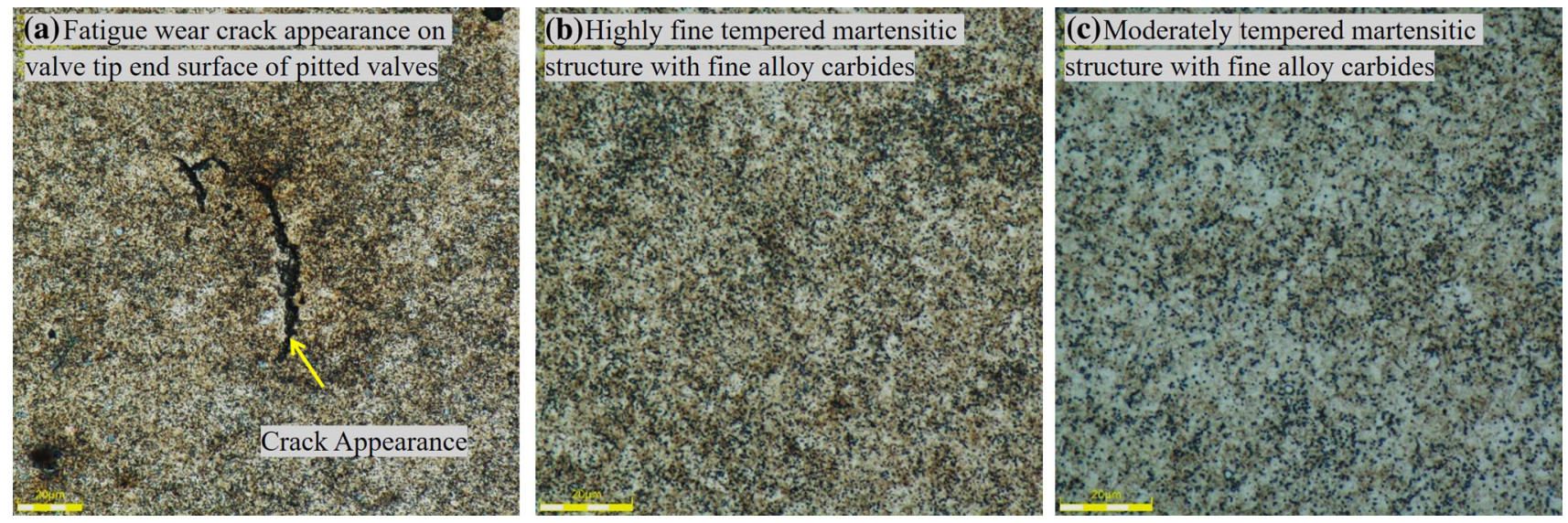

Fig. 10 Microstructure evaluation etched with picral: a fatigue crack appearance on valve tip surface; $\mathbf{b}$ highly fine tempered martensite with fine alloy carbides on pitted valve; c moderately tempered martensite with fine alloy carbides on non-pitted valve

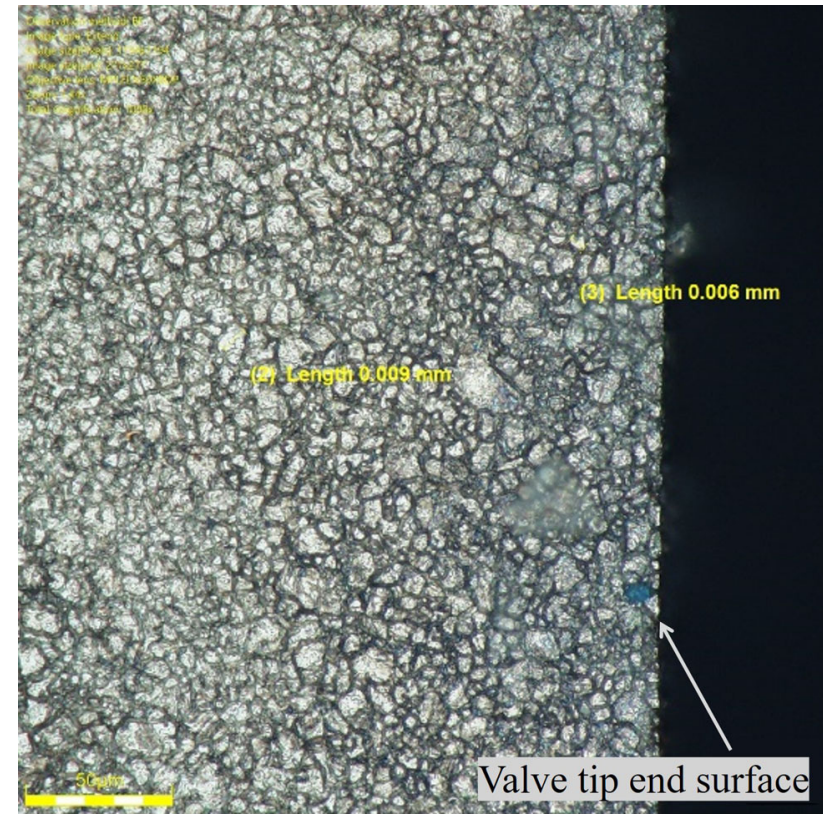

Fig. 11 Prior austenite grain boundaries of hardened martensitic structure

end of all valves with a significantly lower material removal rate. It is necessary to maintain the desired surface roughness for the smooth operation of valve train components.

$\mathrm{X}$-ray diffraction methodology was used to calculate residual stresses on valve tip end surface and subsurfaces. The results show that stresses were compressive at valve tip end surface in all the cases as the tip end grinding is done on the surface with the abrasive wheel in a controlled condition (coolant) to achieve required surface roughness of less than or equal to $0.2 \mathrm{Ra}(\mu \mathrm{m})$. Since the grinding process is done under controlled conditions to avoid excess heat generation, the resultant residual stresses are always compressive on the surface [14].

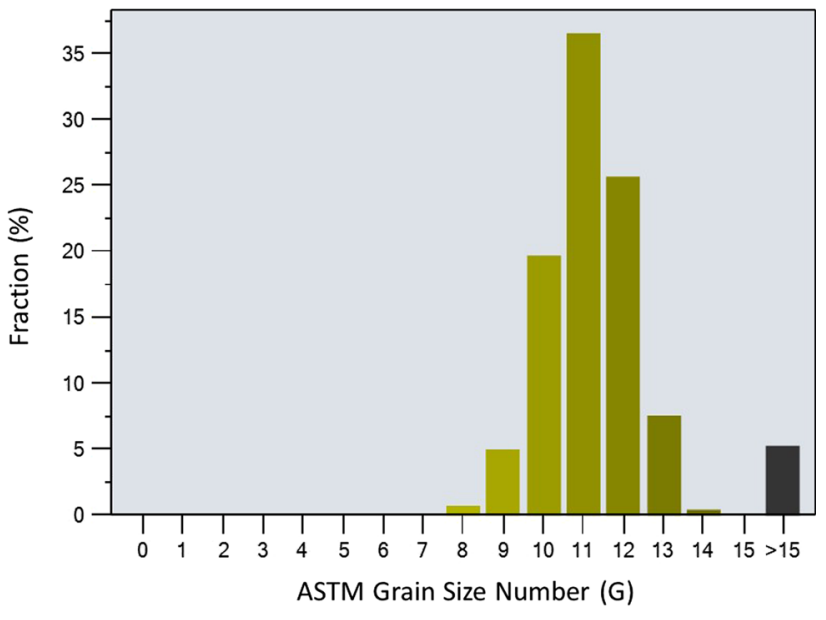

Fig. 12 Histogram of grain size distributions

The X-ray residual stress analysis shows that the absolute values of residual stress in a fresh valve are in the range of 450 to $600 \mathrm{MPa}$ (Compressive) at the surface of the valve tip end. Tested valves in the engine have shown residual stress levels close to $900 \mathrm{MPa}$ on the valve tip end surface, higher than untested valves. It indicates that residual stresses are higher in the type II valve train mechanism. The increased level of compressive residual stress suggests the possible presence of plastic deformation from the tip surface. Overall observation shows that tensile residual stress changes into residual compression stress at the subsurface level as the testing proceeds. However, preexisting tensile stresses have already been supported in the initiation of micropits and their propagation. Before improvement, residual stresses were compressive up to 10 microns depth from valve tip end surface. Preexisting residual tensile stress lowers the fatigue life at the tip for applied stress levels. And it may cause pitting initiation at an early stage of testing, which was evident in the macroscopic image (Figs. 4 and 5). Compressive residual 
stress is desirable up to a certain depth to resist micropits formation and fatigue crack propagation. In the presented case, valves with improvement show residual compressive stress up to 50 microns depth, resulting in improved fatigue strength. The resulting compressive residual stresses are always beneficial in dynamic operating conditions, as they reduce the effects of applied tensile stresses [15]. Hence, the cutoff depth from where residual stresses changes from compressive to tensile is also essential during the tip end hardening process. Countermeasures were provided and implemented during the manufacturing of valves to improve the reliability of the engine valve tip end with this valve train mechanism.

\section{Conclusions and Recommendations}

The detailed investigation shows that pitting has initiated due to the presence of a tensile type of residual stress at the valve tip end subsurface in 10 microns depth. And that led to the creation of microvoids/pits on the valve tip end contact surface. Further, voids have propagated into the material in a fatigued manner, as striations are evident on

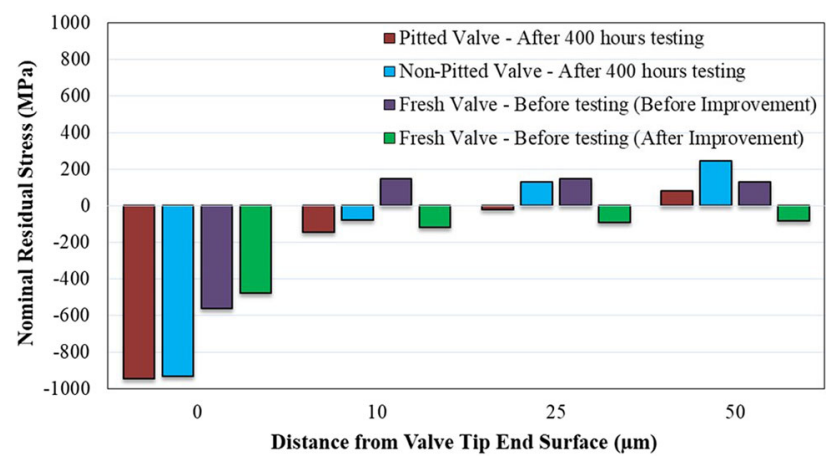

Fig. 13 Plot of residual stress with reference to depth from tip surface

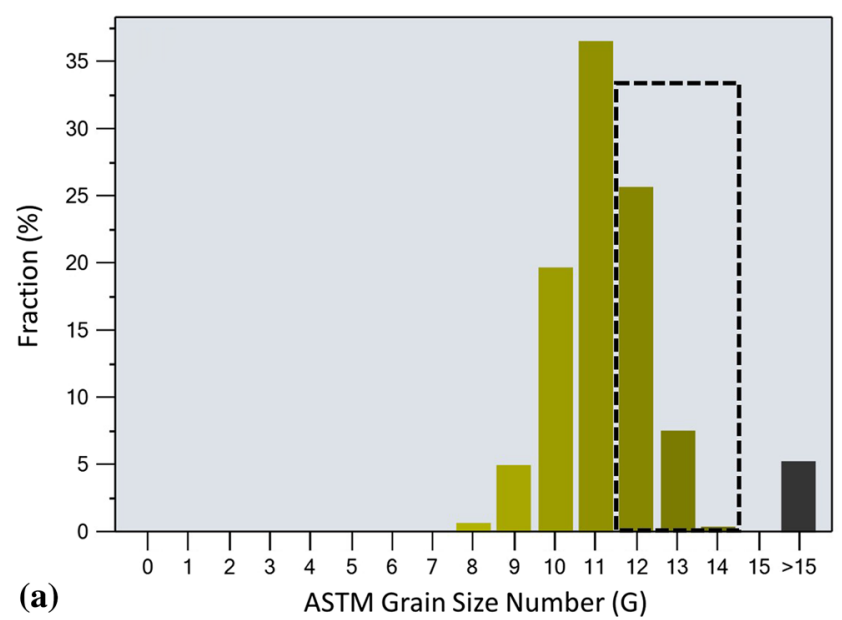

worn surfaces. An increase in the residual compressive stress after 400 hours of testing indicates the higher contact stresses were present at valve tip end/RFF contact.

This pitting phenomenon is not only due to any one cause, but improvement in the below-mentioned parameters together can help to improve the endurance limit of valve tip end properties.

(i) To impart toughness to the martensitic matrix at valve tip end region, an additional stress relief (box furnace) operation was added after the tip end hardening process. The objective was to achieve the compressive type of residual stresses at subsurfaces up to 50 microns depth. The results after additional stress relief are shown in Fig. 13 as fresh valvebefore testing (after improvement). This preexisting residual compressive stress at sub-surfaces would provide extended fatigue life compared to preexisting residual tensile stress. Favorable residual stress gradient has shown itself as an effective countermeasure to improve tip end fatigue wear resistance.

(ii) Hardening temperature increased to achieve higher hardness 60-62 HRC, which is closer to mating component RFF. An increase in hardening temperature can be correlated with an increase in the power of the induction hardening setup.

(iii) ASTM grain size number near tip end surface was found to be 11 to 12 . There is no noticeable increase in the overall grain size number after improvement. Close observation of grain size distributions after improving the hardness reveals that slight grain refinement is evident as the fraction percentage of finer grains increases, as shown in Fig. 14.

The actual testing was conducted on the improvement parts, and testing was completed successfully without any pitting or cracks on any of the valve tip end, as shown in Figure 15.

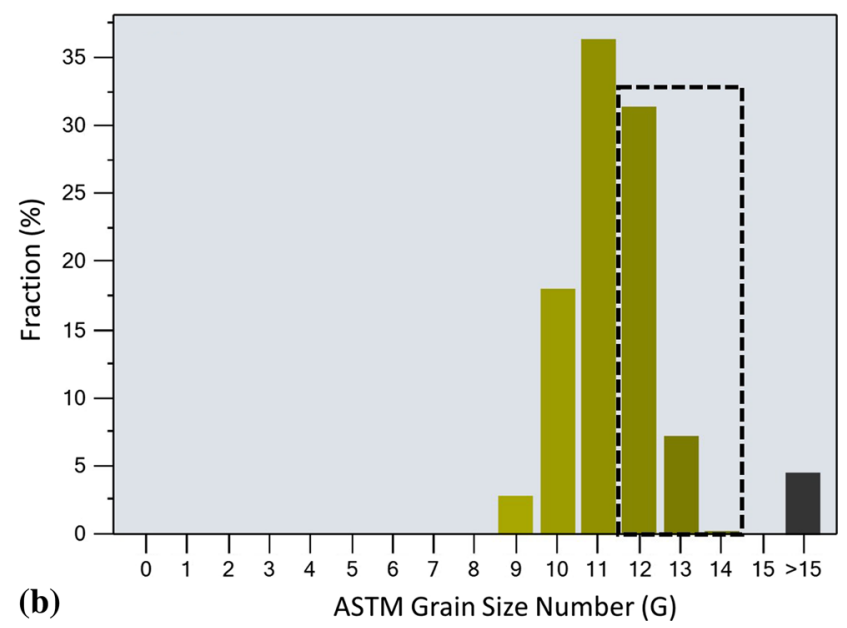

Fig. 14 Grain refinement in valve tip end. (a) Before improvement. (b) After Improvement 

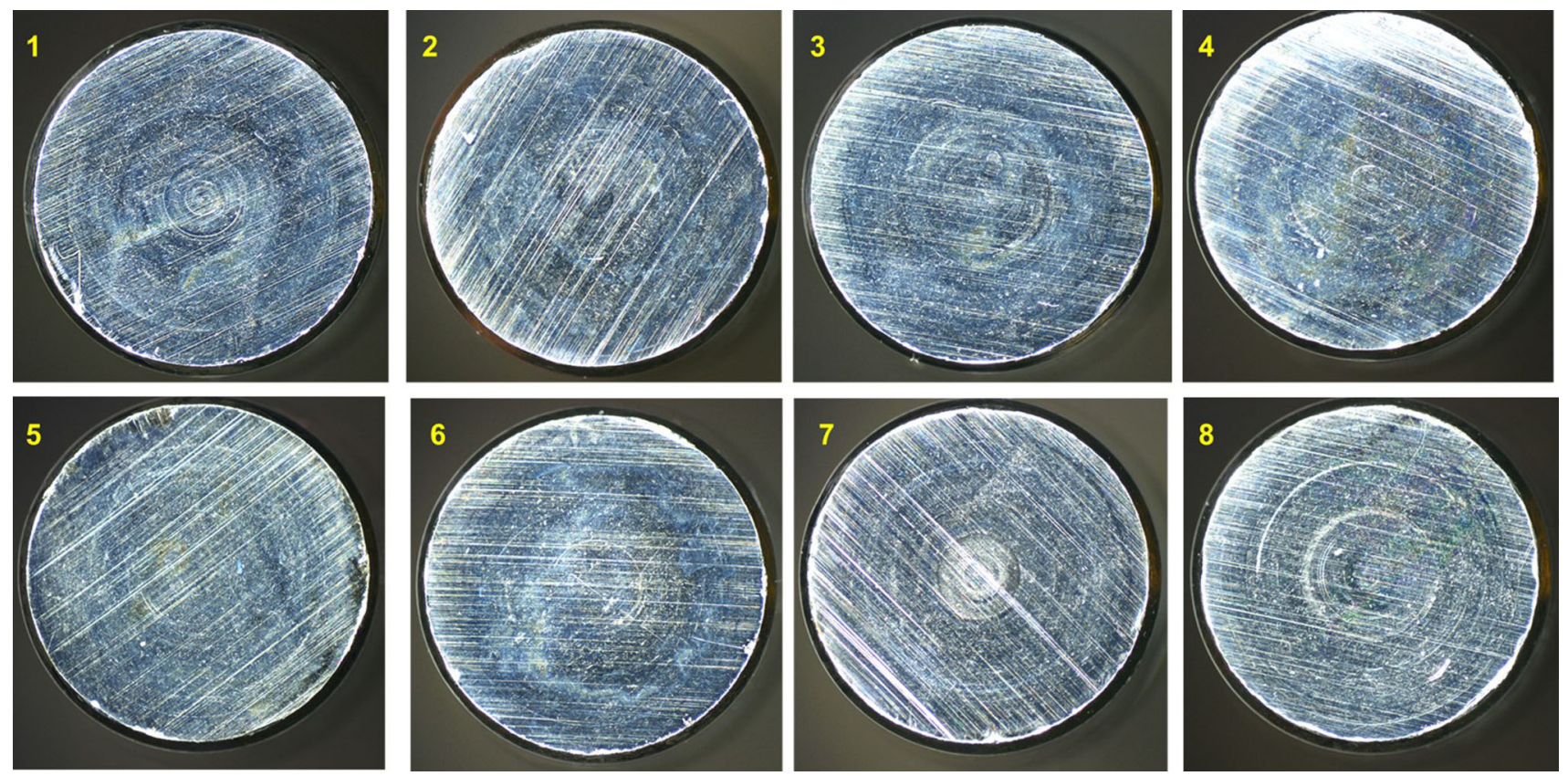

Fig. 15 Visual examination of valve tip ends on improved valves after high-speed test (400 Hours) with same engine configuration—no pitts observed

Open Access This article is licensed under a Creative Commons Attribution 4.0 International License, which permits use, sharing, adaptation, distribution and reproduction in any medium or format, as long as you give appropriate credit to the original author(s) and the source, provide a link to the Creative Commons licence, and indicate if changes were made. The images or other third party material in this article are included in the article's Creative Commons licence, unless indicated otherwise in a credit line to the material. If material is not included in the article's Creative Commons licence and your intended use is not permitted by statutory regulation or exceeds the permitted use, you will need to obtain permission directly from the copyright holder. To view a copy of this licence, visit http://creativecommons. org/licenses/by/4.0/.

\section{References}

1. A. Zurface, S. Brownell, D. Genise, P. Tow, J. Tuttle, Design and Development of a Switching Roller Finger Follower for Discrete Variable Valve Lift in Gasoline Engine Applications. SAE Int. J. Fuels Lubr. 5(3), 1066-1077 (2012)

2. C. Spiegelberg, S. Andersson, Simulation of Friction and Wear in the Contact Between the Valve Bridge and Rocker Arm Pad in a Cam Mechanism. Wear. 261(1), 58-67 (2006)

3. W.T. Becker, R.J. Shipley, S.R. Lampman, B.R. Sanders, G.J. Anton, N. Hrivnak, J. Kinson, C. Terman, K. Muldoon, S.D. Henry, W.W. Scott Jr. ASM Handbook. Failure Analysis and Prevention. (2002) 11:107

4. Z.W. Yu, X.L. Xu, Failure Analysis of Diesel Engine Rocker Arms. Eng. Fail. Anal. 13(4), 598-605 (2006)

5. C. Soffritti, M. Merlin, R. Vazquez, A. Fortini, G.L. Garagnani, Failure Analysis of Worn Valve Train Components of a FourCylinder Diesel Engine. Eng. Fail. Anal. 1(92), 528-538 (2018)
6. M.M. Muhammad, M.C. Isa, M.S. Yati, S.R. Bakar, I.M. Noor, Failure Analysis of a Diesel Engine Rocker Arm. Def S\&T Tech Bull. 3(2), 78-84 (2010)

7. M. Priest, C.M. Taylor, Automobile Engine Tribology-Approaching the Surface. Wear. 241(2), 193-203 (2000)

8. A. Terrin, C. Dengo, G. Meneghetti, Experimental Analysis of Contact Fatigue Damage in Case Hardened Gears for Off-Highway Axles. Eng. Fail. Anal. 1(76), 10-26 (2017)

9. B.J. Yang, A. Hattiangadi, W.Z. Li, G.F. Zhou, T.E. McGreevy, Simulation of Steel Microstructure Evolution During Induction Heating. Mater. Sci. Eng., A. 527(12), 2978-2984 (2010)

10. R. Chattopadhyay. Surface Wear: Analysis, Treatment, and Prevention. ASM International; (2001).

11. A.A. Torrance, J.E. Morgan, G.T. Wan, An Additive's Influence on the Pitting and Wear of Ball Bearing Steel. Wear. 192(1-2), 66-73 (1996)

12. E. Lainé, A.V. Olver, M.F. Lekstrom, B.A. Shollock, T.A. Beveridge, D.Y. Hua, The Effect of a Friction Modifier Additive on Micropitting. Tribol. Trans. 52(4), 526-533 (2009)

13. B. L'Hostis, C. Minfray, M. Frégonèse, C. Verdu, B. TerOvanessian, B. Vacher, T. Le Mogne, F. Jarnias, A.D. D' Ambros, Influence of Lubricant Formulation on Rolling Contact Fatigue of Gears-Interaction of Lubricant Additives with Fatigue Cracks. Wear. 15(382), 113-122 (2017)

14. M.J. Balart, A. Bouzina, L. Edwards, M.E. Fitzpatrick, The Onset of Tensile Residual Stresses in Grinding of Hardened Steels. Mater. Sci. Eng., A. 367(1-2), 132-142 (2004)

15. J. Gru, P. Zerovm. Residual Stresses in Steels After Heat Treatments and Grinding. WIT Press; 1997

Publisher's Note Springer Nature remains neutral with regard to jurisdictional claims in published maps and institutional affiliations. 